\title{
Methods for personal cooling in hot environment used in clothing and wearables
}

\author{
Atanas Vasilev ${ }^{1, *}$ Radostina A. Angelova, and Rositsa Velichkova \\ ${ }^{1}$ Technical University of Sofia, Department of Hydroaerodynamics and Hydraulic Machines, 1000 \\ Sofia, Bulgaria
}

\begin{abstract}
The use of an efficient personal cooling system in hot environments is becoming increasingly popular, as the increased air temperature provokes thermophysiological discomfort, heat stress, reduced productivity and could lead to several health issues. Different methods and devices for personal and local cooling have been developed over the years. The paper summarises the cooling methods applied in clothing and wearable items: phase-change materials, Peltier elements, evaporative cooling, water cooling and hybrid cooling. The local vs total (of the whole body) cooling is examined. The passive and active colling are analysed in terms of advantages, disadvantages and application.
\end{abstract}

\section{Introduction}

In recent years, more and more attention is paid to personal cooling, which allows local cooling of the body or parts of it in a hot environment. The use of an efficient personal cooling system is becoming increasingly popular, but it is known that there have been developments since the early twentieth century [1]. Heat stress is a serious problem, potentially dangerous to the health of workers who perform activities in hot outdoor and indoor environments: in the mining industry, construction, non-ferrous metal foundries, fire safety, military activities, the production of bricks and tiles, glassmaking, smelting of metals and alloys, cosmonautics [2-6].

The natural cooling of the human body is done by sweating. It is a thermophysiological reaction to reduce the temperature of the body's core to $37{ }^{\circ} \mathrm{C}$ in a hot environment so as not to jeopardize the proper functioning of internal organs, and the physical and mental state of man [7]. However, when it is necessary to wear protective clothing (firefighters, founders, welders), due to the presence of textile layers (system of layers), sweat fails to cool the human body sufficiently through the natural process of heat and moisture transfer $[3,8-9]$. Therefore, lack of adequate cooling (often possible only through the head) can have serious consequences for the workers' productivity and health.

That is why people who work in high-temperature conditions have to rely on personal cooling devices increasingly. These devices are expected to reduce heat stress and fatigue and improve productivity and thermophysiological comfort. Indoors, personal cooling

\footnotetext{
* Corresponding author: atanasvasilev9@gmail.com
} 
devices can completely replace HVAC systems in specific situations where the energy costs outweigh their usefulness. On the other hand, the presence of HVAC systems that allow the simultaneous maintenance of the thermal comfort of a large number of occupants (usually at a lower cost) is a kind of constraint on the development of devices and methods of personal cooling. Outdoors, however, personal cooling is the only option.

Over the years, various personal methods and devices for local cooling have been developed. These are mainly cooling clothing items aimed to reduce heat load and tailored to gender, workload, and the other work or protective clothing [10-13]. The most used products are vests or full suits $[5,10,14-16]$. They are active when the garments utulise external cooling sources: electrical components, additional cooling elements and units, and forced blows [3, 6, 8-9, 13, 15]. Passive items are based on applying phase-change materials, frozen gels, ice $[2,5,11,16]$.

The paper summarises the existing methods for cooling the human body using clothing and textile wearables in a hot environment. Passive and active cooling are considered together with local and total cooling of the human body. Furthermore, advantages, disadvantages and application of different methods are discussed.

\section{Working in a hot environment}

According to the definition of the Canadian Center for Occupational Health and Safety [17], an increase in temperature above $27{ }^{\circ} \mathrm{C}$ and relative humidity above $60 \%$ is considered a hot environment. The presumption is that an essential part of people feels comfortable at an air temperature of $20{ }^{\circ} \mathrm{C}$ to $27{ }^{\circ} \mathrm{C}$ and relative humidity of $35 \%$ to $60 \%$. The systematic review in [18] has involved in its analysis of the hot environment all studies conducted in air temperature above $25^{\circ} \mathrm{C}$.

Even though the environment is hot, it only causes thermal discomfort, as long as the body's thermoregulatory system effectively copes with excess heat. If the core temperature rises even by $2-3{ }^{\circ} \mathrm{C}$, the body still retains its functionality [17]. However, side effects can occur that reduce performance, damage health and could even lead to death. Working in such an environment poses a serious threat to human health because physical fatigue also increases due to the rise in body temperature and dehydration. Fatigue can lead to injuries and accidents at work. There is also a loss of concentration, which which can provoke injuries and accidents at work [7].

Such working conditions require a different work regime, including frequent breaks to prevent potential consequences for workers.

\section{Personal cooling in the hot environment}

Personal cooling is related to the cooling of the individual in a hot environment, regardless of the presence or absence of HVAC systems (for indoor environments, including means of transport). It can be provided by personal technical devices, for example, a mini fan connected to the computer. Wearable devices that are connected to and move with the human body can also be used.

Local cooling, in many cases, is synonymous with personal cooling, including in research publications. However, it is associated with cooling parts of the human body: e.g. head, nape, torso therefore, personal cooling items can be local if they provide cooling of a part of the body or total if they cool the whole body. Of course, both local and total cooling effect the thermoregulatory system, causing reactions in the whole body. 


\subsection{Phase-change materials}

Phase-change materials (PCMs) are a passive cooling medium used for local cooling. PCMs are mainly incorporated in clothing items and wearable devices (collars, helmets), worn on the upper part of the human body, namely the torso and the head $[5,11,16,19]$. PCMs are in the form of separate segments (packages), which facilitates their use and their easy replacement. As a part of the protective workwear, the PCM segments do not cause any discomfort. The weight of a cooling vest with PCMs in most cases is up to $3 \mathrm{~kg}$. [11, 16].

Frozen gels, paraffin and salts are mainly used as phase-change materials. For cooling, they are used in their frozen state and have efficiency until the respective material melts. PCMs have a number that indicates the material's melting temperature: i.e. PCM5, PCM10, PCM 15 [16]. Figure 1 shows a microscope view of polyester fibres with incorporated PCM (courtesy of COutlast Technologies GmbH).

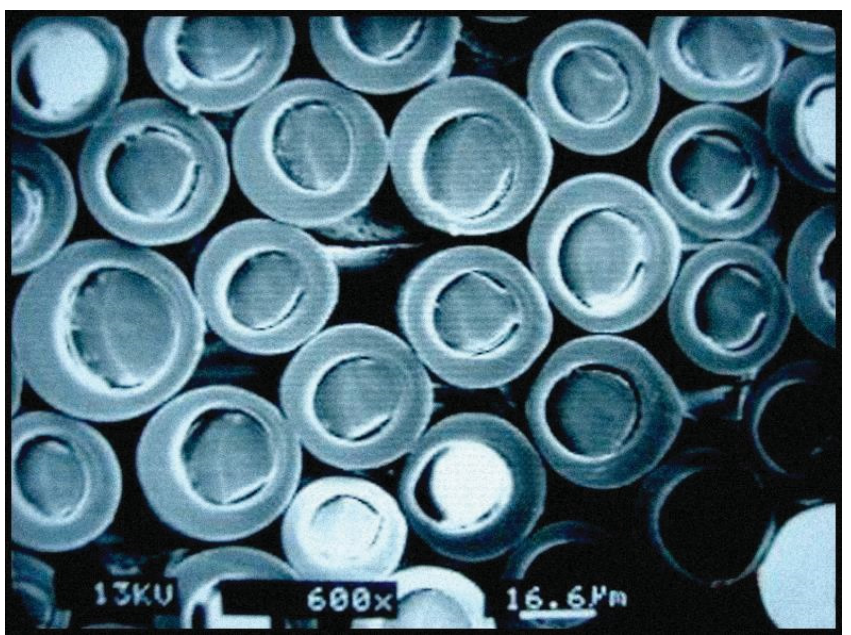

Fig. 1. Polyester fibres with PCM (courtesy of COutlast Technologies GmbH)

The application of PCMs in clothing and wearables for personal cooling in hot environments is very large. Belonging to the passive cooling methods, it is one of the most commonly used in various work environments, sports and other physical activities due to easy maintenance and relatively good efficiency over time.

\subsection{Peltier elements}

The Peltier element is a semiconductor composed of a large number of semiconductor pairs of two different materials - Fig. 2. When voltage is applied to one side of the element, it is heated while the other is cooled. This makes it a universal source of heat and cooling. 


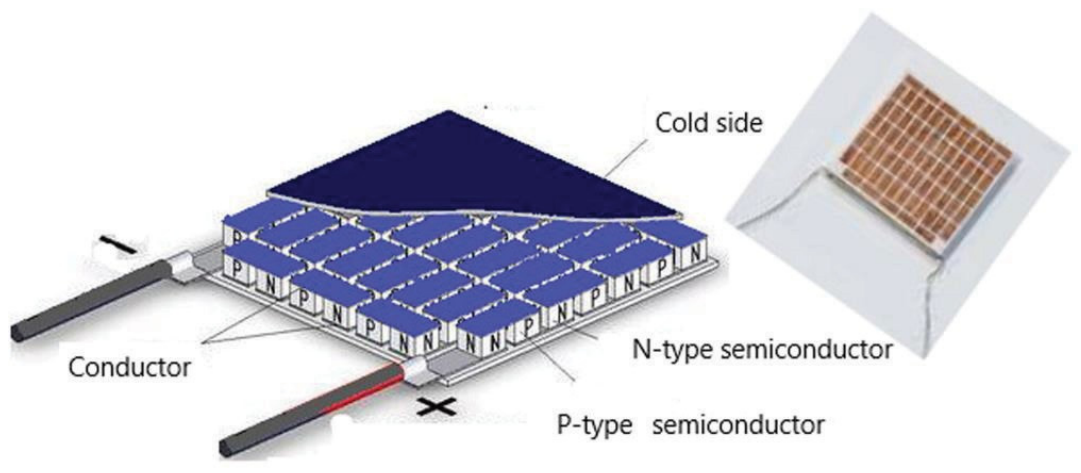

Fig. 2. Peltier element

Peltier elements are mainly used for cooling: the heat received from its heated surface is removed through a fan. Being a high-efficiency tool, they are common in cooling systems with a negligibly small volume. This is one of the most common methods for active cooling, used in clothing and wearables for both local and total cooling of the human body. There are design ideas for local stationary cooling in a closed system with a cold water carrier and total cooling in a mobile suit with a system of fans and built-in air duct elements $[3,8,20]$.

\subsection{Evaporative cooling}

Evaporative cooling is an active cooling technique. Evaporative cooling vests have a builtin evaporative microenvironment, created in an intermediate layer, located between the cooling vest and human skin. The vests are focused on cooling the back of the torso. The released by the human body sweat is absorbed into highly hygroscopic layers. Thanks to the forced introduction of hot air from the environment with the help of small fans, sweat evaporates, thus assuring the cooling process.

Two types of evaporative cooling vests have been developed - a single evaporative cooling channel vest and a Maisotsenko cycle (M-cycle) vest [9]. They differ mainly in that the M-cycle technique uses two channels: a dry and evaporative channel. The M-cycle provides faster evaporation and thus better cooling because the sweat absorbed in the hygroscopic layer is subjected to double heating - once by the human body and a second time by the air, which once entered the inlet channel begins to give off heat. The formation of two channels is done by using a thin conductive fabric to transfer heat from the inlet channel to the outlet [9]. Figure 3 shows the design of the evaporative cooling vest (courtesy of (C) TechNiche LLC).

\subsection{Water cooling}

Water cooling is another type of personal cooling methods designed to cool both locally or the whole body. The system is active, using a cold carrier - a mix of ice and water.

The water cooling wearables (suits or vests) are equipped with a backpack tank of water and ice mixture. The tank is well insulated to minimize the impact of weather conditions on its efficiency over time. The suit or vest is supplied with water via hoses running throughout the garment and are integrated into it - Fig. 4. The used water circulates forcibly with the help of a pump powered by a portable battery. The cooling clothing item is made 
of highly elastic textile materials, making it comfortable to wear without affecting human motions [15].

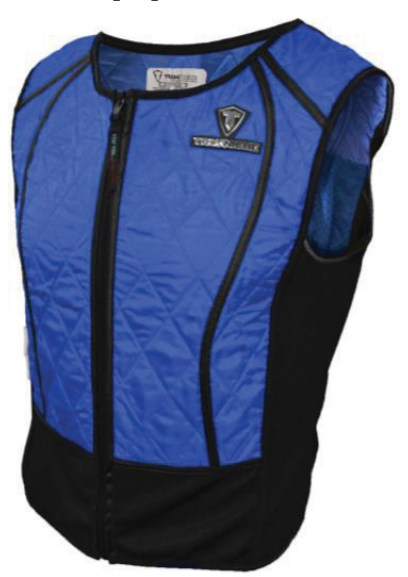

Fig. 3. Evaporative cooling vest (courtesy of (C) TechNiche LLC)

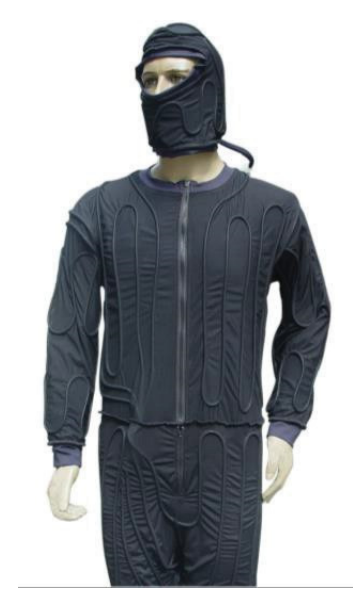

Fig. 4. Water cooling suit (courtesy of (C)BateryHeatedClothing.com)

\subsection{Hybrid cooling}

The hybrid personal cooling systems belong to the active cooling methods and are focused on cooling the whole body. They use dry ice and air ventilation [9]. The textile layers for the suits are specially selected to be with close to zero permeability. An almost hermetically sealed volume is obtained inside the suit, which volume can be defined as an air cushion between the human body and the hot environment - Fig. 5. Dry ice is placed in specially designed pockets. In addition, fans are used to move the air around the pockets with ice. Thus, they reduce the temperature in the air cushion and cool the human body.

Fig. 5. Hybrid cooling principle

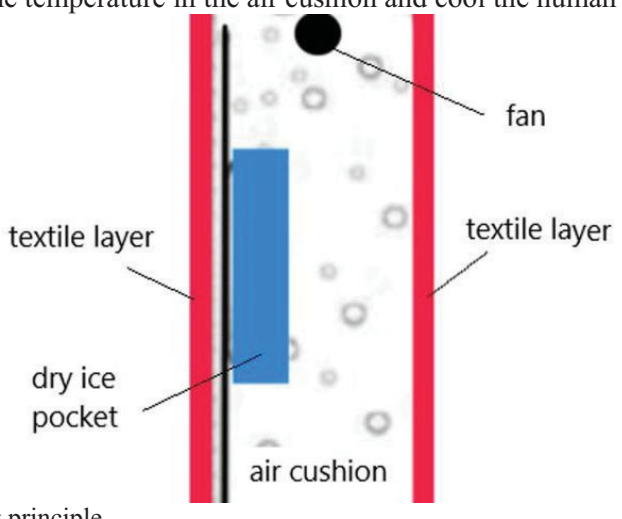




\section{Passive vs active cooling clothing and wearables}

The passive cooling clothing items and wearables are among the most common personal cooling devices. Their design is relatively simple. The clothes are made so that the installation and replacement of the cooling source are rapid and easy; in most cases, there are additional pockets in which the cooling elements are placed. If the environment does not require constant cooling of the human body, passive clothing and wearables find more application than active ones.

The main disadvantage of the passive cooling methods is that the cooling elements depend on additional cooling devices - refrigerators or freezers, in which to store before their operation. Another disadvantage is that they ensure local cooling since the cooling source is fixed in a particular area. That is why passive cooling clothing and wearables are not particularly preferred and are not widely used in hot environments with constantly high temperatures. In addition, local cooling can impair the comfort of the wearer. Last but not least condensation appears when the cooling packages melt, which is also a disadvantage.

The efficiency of the active colling clothing and wearables is significantly higher, and their application is wider than the passive cooling clothing and wearables because of the applied working principle. The cooling is done by a system of hoses, a circulating pump, fans and a cooling source, which increases the cooling efficiency. Thanks to these components, the cooling is not localized on a specific area but is evenly distributed and covers the entire area of the cooling garment.

The main disadvantage of the active cooling method is that a single failure in the cooling system may require replacing the entire cooling item. In most cases, the components used in the system are embedded in the various layers of the clothing system, and their replacement is tedious, if possible, at all. The power source also limits the efficiency.

From the point of view of maintenance, passive cooling clothing and wearables are far easier to maintain and clean than active ones. The reason is that the cooling elements are easily removed. With active cooling vests and suits, due to the many components in them, maintenance and cleaning must be carried out with great care; otherwise, damage to the cooling system could occur during washing. For example, in cooling clothing with a builtin hose used to circulate the coolant, detergent may get inside the hose if the inlet and outlet remain open when washing. It could reduce the cooling efficiency during operation and even damage a component of the cooling system.

\section{Local vs total cooling clothing and wearables}

The considered examples showed that the cooling clothing are local (vests) and total (suits). The wearables (collars, scarves, helmets) are used for local cooling only.

The vests are very practical, light and comfortable and much more used than cooling suits. However, due to their limited size, they cannot cover a large part of the human body, leading to thermal discomfort or thermal stress.

Suits are far more preferred in work environments where the human body needs constant protection against high temperatures because, unlike vests, they cover almost the entire body and the possibility of thermal discomfort or hot stress is avoided.

\section{Conclusions}

Different solutions related to the personal cooling of the human body in a hot environment have been presented. The existing cooling methods, applied in clothing and wearable items: 
PCMs, Peltier elements, evaporative cooling, water cooling and hybrid cooling, were summarised and discussed. The local vs total cooling was examined. The passive and active cooling was analysed in terms of benefits, disadvantages and application.

The paper is supported by a PhD project grant from the Technical University of Sofia.

\section{References}

1. C.A. Wellman, Body-ventilating apparatus (US Patent 776003, 1904).

2. Y. Yang, J. Stapleton, B.T. Diagne, G.P. Kenny, C.Q. Lan, C. Q., Appl Therm Eng, 47, 18-24 (2012).

3. M. D’Angelo, J. D’Angelo, M. Almajali, K. Lafdi, A. Delort, M. Elmansori, Energ Converse Manage, 79, 140-145 (2013).

4. M. Morrissey, F. Wang, Air and water perfusion-based personal cooling systems (PCSs) to protect against heat stress in protective clothing (Woodhead Publishing, 2014).

5. M. Itani, D. Ouahrani, N. Ghaddar, K. Ghali, W. Chakroun, Build Environ, 107, 29-42 (2016).

6. C. Al Sayed, L. Vinches, S. Hallé, Therm Sci Eng Prog, 11, 1-7 (2019).

7. R.A. Angelova, Environmental Exposures and Human Health Challenges (IGI Global, 2019).

8. I. Sahta, I. Baltina, J. Blums, V. Jurkans, The control of human thermal comfort by the smart clothing. In SHS Web of Conferences (Vol. 10, p. 00040). EDP Sciences (2014).

9. R. Raad, M. Itani, N. Ghaddar, K. Ghali, Int J Therm Sci, 142, 1-13 (2019).

10. Y. Yang, J. Stapleton, B.T. Diagne, G.P. Kenny, C.Q. Lan, Appl Therm Eng, 47, 18-24 (2012).

11. F. Mneimneh, C. Moussalem, N. Ghaddar, K. Ghali, I. Omeis, J Therm Biol, 91, 102634 (2020).

12. R. Iwata, T. Kawamura, Y. Hosokawa, L. Chang, K. Suzuki, I. Muraoka, J Therm Biol, 94, 102746 (2020).

13. S. Del Ferraro, T. Falcone, B.M. Rondinone, V. Molinaro, Int J Ind Ergonom, 75, 102895 (2020).

14. T. Yoshida, H. Shin-ya, S. Nakai, H. Ishii, H. Tsuneoka, The effect of water-perfused suits and vests on body cooling during exercise in a hot environment (Elsevier Ergonomics Book Series 2005).

15. F. Wang, C.S.W. Chow, Q. Zheng, Y. Ke, B. Yang, X. Zheng, ... H. Zhou, Energ Buildings, 205, 109561 (2019).

16. H. Pourghayoomi, H. Dehghan, M.J. Tarrahi, Health Scope, 9(2) (2020).

17. S. Munten, S. Dorman, D. Gagnon, Guide to thermal stress in the workplace (Laurentian University, ON Canada, 2021).

18. A. Ruddock, B. Robbins, G. Tew, L. Bourke, A. Purvis, Sports Med, 47, 517-532, (2017).

19. M. Zhao, C. Gao, F. Wang, K. Kuklane, I. Holmer, J. Li, Text Res J, 83, 418-425 (2013).

20. H. Yang, B. Cao, Y. Ju, Y. Zhu, Energ Buildings, 198, 528-541 (2019). 